\section{Africa: war against health}

\section{Len Goodwin}

'Bid the Sickness Cease': Disease in the History of Black Africa.

By Oliver Ransford.

John Murray: 1983. Pp.235. £12.50.

Take up the white man's burden, The savage wars of peace. Fill the mouths of famine And bid the sickness cease.

Kipling has gone out of fashion and, as the author of this book says, his most maligned poem may sound ridiculously quaint and hypocritical nowadays. Nevertheless, there was far more than arrogance and greed in the European Powers' attitude to the African peoples after the intrusions of the 1880 s. There was also a growing philanthropic impulse to improve the standards of living and health of faraway subjects, and many men and women volunteered to serve in the administration or the missions although they knew that, for many of them, a posting to Africa was a sentence of death.

Dr Ransford himself joined the Colonial Medical Service in 1938 and served first in Nyasaland (Malawi) and later in Rhodesia (Zimbabwe) where he still lives. In 'Bid the Sickness Cease' he traces the history of Black Africa and the effects upon its peoples of the spread of disease, both endemic and epidemic, brought about by migrations that followed tribal wars, the slave trade and, most profoundly, the opening up of the continent by Europeans when protection from malaria by quinine enabled them to survive journeys into the interior.

Spread of originally localized indigenous infections such as trypanosomiasis, and murderous epidemics of smallpox, plague, measles and influenza made the years between 1885 and 1930 the most unhealthy period of African history - in one area of French West Africa the population decreased from 20 million in 1911 to 2.5 million in 1931. In this respect, however, Africa did better than the Amerindians or the Pacific aborigines, whose populations never recovered from the savagery of introduced epidemics.

The author deals with the principal communicable infections of Africa malaria, sleeping sickness, yellow fever and bilharzia -, lesser terrors such as malnutrition, leprosy, yaws, dysentery anc' filariasis, and epidemics of plague, cholera, influenza, cerebrospinal fever and smallpox. He outlines, en passant, the natural history of the parasites responsible, and the biographies of the major personalities associated with their discovery. These are sensitively and often humourously done; he even evokes some sympathy for the impossible, obsessional Ross and the arrogant Bruce, and he gives a scrupulously fair account of the first-class row that developed with Castellani over the discovery of the trypanosome as the cause of sleeping sickness. The structure of the argument makes the book interesting and easy to read, and scattered snippets of recondite information give it colour and perspective. Ransford's deep, but not slushy, understanding and feeling for his patients and their problems runs throughout. He has read and consulted widely and there are few errors - mostly quibbles raised by the simplification of complex or debatable material.

But what of the future? Dr Ransford has confidence in the efforts of the World Health Organization to bring about "Health for all by the year 2000 ", although he warns that time is short and that WHO had better hurry up. More effective medicines and vaccines are urgently needed, and the pharmaceutical industry is not yet sufficiently interested in producing them - the research is difficult, expensive and chancy, new discoveries are pirated by others who have spent nothing on research and development, and the people who need the drugs are too poor to pay for them anyway. Unless measures are taken soon by

\section{Simply gauge theory}

\section{John Ellis}

\section{An Informal Introduction to Gauge Field} Theories.

By I.J.R. Aitchison.

Cambridge University Press: 1982.

Pp.171. £12.50, \$22.50.

IAN Aitchison has previously written with A.J.G. Hey a useful introductory text on gauge theories, suitable for experimental students. The present volume aspires to fill a gap between that earlier book and the more advanced treatises such as that by Itzykson and Zuber. It is intended for novices to the subject such as graduate students and outsiders (cosmologists perhaps?) who might want to learn about gauge theories because of their significance for their own field.

Aitchison is an experienced and greatly appreciated teacher who has often taught graduate courses and lectured at summer schools. His selection of material and manner of presentation is undoubtedly influenced by these experiences, and responds to a genuine need. Nonetheless, although I find the concept of the book appealing, and much of the material well selected, I do have some reservations about the way it is presented.

Aitchison starts with a somewhat sparse chapter on the motivations for studying gauge theories, and then comes back to their applications at various points in the text. I found this approach a little un- the Northern countries to improve the standards of living and the economies of the South - as emphasized in the Brandt Report - crisis is imminent for the North as well as the South.

But the major obstacle to health in Africa is political instability. As Ransford says, with the coming of independence to the ex-colonial territories, Africa has now taken its place in world affairs and has begun to move into a future of its own making; but great vision is needed, and development can only take place in a continent at peace within itself. This, at present, is not a reality. William $\mathrm{McNeill}$ in his book Plagues and Peoples (on which Ransford draws for his historical perspectives) has shown how diseases spread by the movements of armies and refugees and the destruction of agricultural communities by war have profoundly affected the course of history. All this is still going on in Africa and there seems to be little hope for health by the year 2000 unless someone can bid the fighting cease.

Len Goodwin was formerly at the Wellcome Laboratories of Tropical Medicine and later Director of Science at the Zoological Society of London. Now retired, he is a part-time consultant to the World Health Organization.

settling, and it would perhaps have been better either to drop the accounts of motivations and applications entirely, or else to discuss them more coherently and completely. The author then introduces symmetry in quantum field theory in some detail, a topic which would not appear to present great difficulties. I know from experience, however, that students often appreciate such a systematic approach.

The sections on gauge theories and their quantization do not employ the path integral formalism. It is perhaps a matter of taste whether this omission is sensible nowadays, but it may be appropriate at this introductory level. The book concludes with a section on renormalization, but this is incomplete in that there is no discussion of the renormalization of non-Abelian gauge theories. Why not calculate the $\beta$. function?

The book is also marred by some niggling slips. The Noether theorem is only called by its name several pages after its proof. The punctuation is sometimes baroque - see an egregious sentence on p.30, for example. Some distinguished physicists' names are consistently misspelt. And the mass of the charm quark was originally estimated from $\mathrm{K}_{1} \mathrm{~K}_{2}$ mixing, not from $\mathrm{K}_{\mathrm{L}}^{0} \rightarrow \mu^{+} \mu^{-}$as asserted on p.119.

Despite these minor defects, newcomers to the subject may find the book useful, though I think most theoretical students will prefer to consult more advanced texts.

John Ellis is at the Stanford Linear Accelerator Center, Stanford, California. 